\title{
ELECTRODE WEAR RATE OF GRAPHITE ELECTRODES DURING ELECTRICAL DISCHARGE MACHINING PROCESSES ON TITANIUM ALLOY TI-5AL-2.5SN
}

\author{
Md. Ashikur Rahman Khan ${ }^{3}$, M. M. Rahman ${ }^{1,2^{*}}$ and K. Kadirgama ${ }^{1}$ \\ ${ }^{1}$ Faculty of Mechanical Engineering, University of Malaysia Pahang, \\ 26600 Pekan, Pahang, Malaysia \\ ${ }^{2}$ Automotive Engineering Centre, University of Malaysia Pahang, \\ 26600 Pekan, Pahang, Malaysia \\ *Email: mustafizur@ump.edu.my \\ Phone: +6094246239; Fax: +6094246222 \\ ${ }^{3}$ Department of Information and Communication Technology \\ Noakhali Science \& Technology University, Bangladesh
}

\begin{abstract}
The proper selection of machining parameters can result in better machining performance in the electrical discharge machining process. However, this job is not always easy since the phenomena occurring between the electrodes in EDM are not yet fully understood. This study reports the development of a comprehensive mathematical model for the electrode wear rate (EWR) of a graphite tool in EDM on Ti-5Al-2.5Sn alloy, which has not yet been presented. Experiments for positive polarity of the graphite electrode, based on design of experiment (DOE), are first conducted. Modeling and analysis are carried out through the response surface methodology, utilizing the experimental results. A confirmation test is also executed to confirm the validity and the accuracy of the mathematical model developed. The confirmation test exhibits an average error of less than 6\%. Negative electrode wear is evidenced for particular settings. The combination of $15 \mathrm{~A}$ peak current, $350 \mu$ s pulse-on time, $180 \mu$ s pulse-off time and $95 \mathrm{~V}$ servo-voltage and positive polarity causes negative tool wear. It is apparent that the developed model can evaluate electrode wear rate accurately and successfully.
\end{abstract}

Keywords: Graphite, Electrode wear rate, Ti-5Al-2.5Sn, EDM

\section{INTRODUCTION}

Titanium alloy (Ti-5Al-2.5Sn) was selected for the present study on the basis of its use in a wide range of applications. It offers a reduction of aircraft weight. Titanium alloys have many uses, yet there is a key problem in machining when using conventional techniques such as turning, milling, drilling, grinding, and reaming (Khan, Rahman, Kadirgama, \& Ismail, 2012; Khan, Rahman, Kadirgama, Maleque, \& Bakar, 2011b; Rahman, Khan, Kadirgama, Noor, \& Bakar, 2010b, 2011a; Rahman, Khan, Noor, Kadirgama, \& Bakar, 2011b). One of the crucial difficulties in cutting a hard material like titanium alloy is tool wear (Rahman Khan, Rahman, Kadirgama, \& Ismail, 2012; Rahman et al., 2011a). In fact, titanium and its alloys are difficult to machine in comparison with steel and aluminum alloys by all conventional machining methods. This is due to a number of the inherent properties of titanium alloys. Titanium alloys 
introduce heat, deflection, galling and welding, chatter, and vibration during cutting operations due to their low modulus of elasticity and thermal conductivity, and their chemical reactivity. High temperatures, rapid tool wear, short tool life and high costs are thus associated with the conventional machining of titanium alloys (Rahman, Khan, Kadirgama, Noor, \& Bakar, 2010a; Rahman et al., 2010b). High cutting temperatures and strong adhesion between the tool and work-piece material increase tool wear. A number of researchers have attempted to machine these materials with different cutting tools such as straight-grade cemented-carbides (Wo-Co), polycrystalline diamond (PCD), straight tungsten-carbide tools, cemented TiN tools, pure aluminum-oxide ceramic tools, TiC-coated tools, cubic boron nitride (CBN), sintered diamond tools, and natural diamond tools. During machining, the cutting temperature of the titanium alloy was raised to $727{ }^{\circ} \mathrm{C}-1077{ }^{\circ} \mathrm{C}$, even at a low cutting speed. Of all these cutting tools, the ceramic and $\mathrm{CBN}$ tools resulted in the most excessive wear. This wear can cause a chemical reaction, and even adhesion, between the tool and workpiece materials. A similar performance was observed in the case of sintered diamond tools. Although diamond tools yield low wear rates, the cutting operation cannot be continued since the temperature at the soldered part of the tip exceeds the melting point. In addition to these difficulties, the higher cost of these special tools limits the conventional machining of titanium alloys. Although the above-mentioned tool materials seem to be effective in machining, they cannot be recommended for the machining of titanium and its alloys (Hascalik, Caydas, \& Gurun, 2007; Kumar \& Singh, 2010; Singh \& Singh, 2011). It is recognized that electrical discharge machining can be used effectively in machining hard, high-strength, and temperature-resistant materials (Khan, Rahman, Kadirgama, Maleque, \& Ishak, 2011c; Najiha, Rahman, Kamal, Yusoff, \& Kadirgama, 2012; Yusoff, Mohamed Suffian, \& Taib, 2011). EDM is also a process that demands expertise, and the mechanism of metal erosion during sparking is not fully understood due to the complex thermal conduction behaviors in the machining vicinity (Wang et al., 2012). Accordingly, it has been hard to establish models that accurately correlate the process variables and performance. The parameter settings given by the manufacturers are only applicable to the common steel grades (Khan et al., 2011b). A single parameter change influences the process in a complex way. Modelling the process is an effective way of solving the tedious problem of relating the process parameters to the performance measure (Perazolli, Simoes, Coleto, \& Moura Filho, 2005).

Numerous work has been performed towards correlating the EDM process parameters and the performance characteristics. Many researchers have also attempted to investigate the impact of the process parameters on the performance characteristics. The influence of EDM parameters on electrode wear (EW) was analyzed when conducting the machining on cemented carbide or hard metal such as 94WC-6Co (Perazolli et al., 2005). Quadratic models were developed for the resulting electrode wear. It was noted that in the case of tool wear, the intensity factor is the most influential, followed by its own pure quadratic effect and the interaction effect of intensity and pulse time. A semi-empirical model for tool wear was presented for various workpiece and tool electrode combinations (Dave, Desai, \& Raval, 2012). This model was established by employing dimensional analysis based on process parameters, which were screened by design of experiments. Modelling, and analysis of the effects of machining parameters on the performance characteristic as electrode wear rate in the $\mathrm{EDM}$ process of $\mathrm{Al} 2 \mathrm{O} 3+\mathrm{TiC}$ mixed ceramic, were carried out using response surface methodology (Rahman, 2011). Central composite design (CCD) was adopted for 
experiment plan. It was shown that the discharge current, and the pulse-on time have a statistically significant effect on electrode wear rate. (Dave et al., 2012; Rahman Khan et al., 2012) developed a regression equation for EDM performance characteristics of $70 \% \mathrm{WC} / 30 \% \mathrm{Co}$ through design of experiments and statistical analysis. A study was conducted to investigate the effect of current and tool dimension on the EDM characteristics of a mild steel work piece (Dave et al., 2012). The response variables were predicted using regression analysis and artificial neural network techniques. In another study, (Khan et al., 2011a) modelled the performance characteristics in EDM on AISI D2 tool steel taking into account four input variables: discharge current, pulse duration, pulse-off time and applied voltage. For this, experimentation and analysis were performed in accordance with central composite design (CCD) along with response surface method. Mathematical models were developed for correlating the various machining parameters and one of the most dominant machining criteria was electrode wear ratio (Khan et al., 2011a). Optimal combinations of the process parameters were obtained for achieving the controlled electrical discharge machining of the workpieces utilizing response surface method.

Although a number of investigations and studies have been conducted, to the best knowledge of the authors and according to a literature study, a relationship between the electrode wear of graphite tools and the process variables in the EDM process on Ti5Al-2.5Sn is still lacking. One existing model cannot be used for new or dissimilar material, and experimental investigations are always required. This research work therefore concentrates purely on the electrode wear of graphite tools. The present paper emphasizes the development of mathematical models for correlating the various machining parameters, namely peak current, pulse-on time, pulse-off time, and servo voltage on, one of the most significant criteria - electrode wear rate. It also aims to determine the values of the selected parameters, which cause less tool wear on the graphite electrode during the electrical discharge machining of selected titanium material.

\section{EXPERIMENTAL SET UP}

\section{Design of Experiment}

The present study aims to assess the correlation between the electrode wear rate of a graphite electrode in EDM process on titanium alloy Ti-5Al-2.5Sn. Response surface methodology was employed throughout the experiment to build the connection between the electrode wear rate and process parameters such as peak current, pulse-on time, pulse-off time and servo-voltage. For this reason, the experiment was accomplished according to design of experiment, since design of experiment provides an advantage in saving time and costs by reducing the number of experiments (Najiha et al., 2012). Axial point central composite design (CCD) was adopted as design of experiment. When using these methods, there is a possibility that the experiments will stop after a few runs and it will be decided that the prediction model is satisfactory. The four factors, peak current, pulse-on time, pulse-off time and servo voltage, are chosen as independent process variables in accordance with the literature consulted and EDM characteristics, as well as preliminary experimentations. The effects of the parameters considered were verified through preliminary experiments. The low and high levels of the process variables are given in Table 1. Accordingly, the five levels of peak current were set at 1, 8, 15, 22 and $29 \mathrm{~A}$, those of pulse-on time were set at 10, 95, 180, 265 and 
$350 \mu \mathrm{s}$, those of pulse-off time set at $60,120,180,240$ and $300 \mu \mathrm{s}$, and the levels of servo voltage were set at $75,85,95$ and $115 \mathrm{~V}$. A total of 93 experimental runs, including two replications, were thus conducted as the main experiments. The mean value of measured electrode wear rate was selected. During experiments, the remaining machining parameters were kept constant.

Table 1. Process parameters and their levels.

\begin{tabular}{clcc}
\hline Designation & Process parameters & \multicolumn{2}{c}{ Levels } \\
\cline { 3 - 4 } & & Low $(-2)$ & High $(+2)$ \\
\hline$X_{1}$ & Peak Current, $I_{p}(\mathrm{~A})$ & 1 & 29 \\
$X_{2}$ & Pulse-on time, $T_{\text {on }}(\mu \mathrm{s})$ & 10 & 350 \\
$X_{3}$ & Pulse-of time, $T_{\text {off }}(\mu \mathrm{s})$ & 60 & 300 \\
$X_{4}$ & Servo voltage, $S_{v}(\mathrm{~V})$ & 75 & 115 \\
\hline
\end{tabular}

\section{Experimental Procedure}

The workpiece material was titanium alloy Ti-5Al-2.5Sn with the following composition: $0.02 \% \mathrm{C}, 0.15 \% \mathrm{Fe}, 2.6 \% \mathrm{Sn}, 5.1 \% \mathrm{Al}$ and rest Ti. To develop the relationship between various EDM process parameters and electrode wear rate, a cylindrical graphite electrode of $20 \mathrm{~mm}$ diameter and $50 \mathrm{~mm}$ length was used for machining the work sample. Kerosene was selected as a dielectric because of its high flash point, good dielectric strength, transparent characteristics, low viscosity and specific gravity (Najiha et al., 2012). Each experiment was conducted at a fixed supply voltage, $120 \mathrm{~V}$, and at a constant dielectric flushing pressure of $0.15 \mathrm{MPa}$. The experimental set up is shown in Figure 1. A new set of workpiece and graphite tool was applied for each run. The full set of runs, according to the design of experiment, were carried out in a state of positive polarity. To evaluate electrode wear rate, the electrode was weighed before and after machining using a digital single pan balance (maximum capacity $=210 \mathrm{gm}$, precision $=0.1 \mathrm{mg}$ ), and is reported in units of gm. Electrode wear rate was calculated by measuring the average amount of the electrode eroded and the machining time as follows (Najiha et al., 2012):

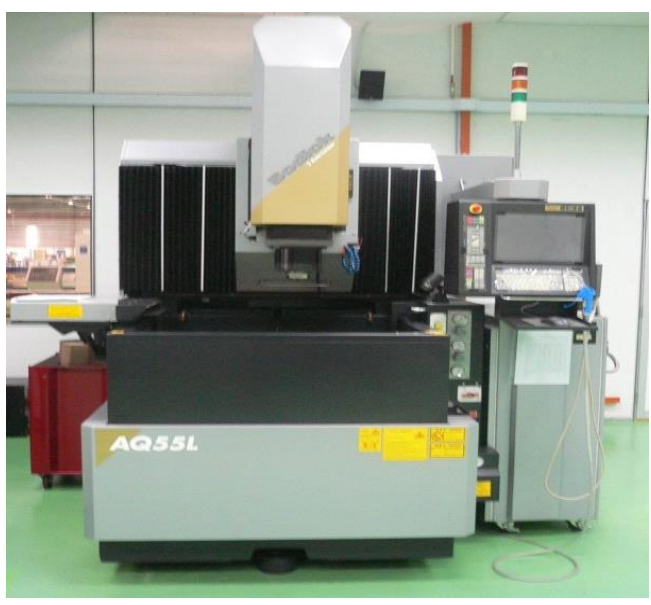

(a)

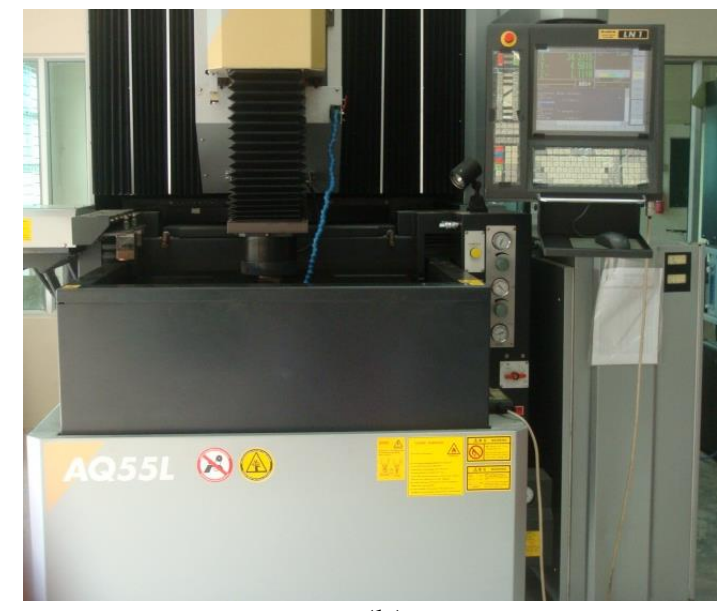

(b)

Figure 1. Experimental set up: (a) before machining, (b) during machining 


$$
E W R=\frac{1000 \times W_{e}}{t} \mathrm{mg} / \mathrm{min}
$$

where $W_{e}=W_{1}-W_{2}$

$W_{e}$ is the weight loss of the electrode in gm,

$W_{l}$ is the weight of the electrode before machining in gm,

$W_{2}$ is the weight of the electrode after machining in gm

$t$ is the machining time in minutes.

\section{MATHEMATICAL MODELLING}

Response surface methodology is an assortment of mathematical and statistical techniques that are useful for the modelling and analysis of problems in which a response of interest is biased by several variables and the objective is to optimize this response (Kadirgama, Noor, Rahman, Bakar, \& Hossein, 2009). It is a sequential experimentation strategy for empirical model building and optimization. A model of the response to independent input variables can be acquired by carrying out experimentation and applying regression analysis. In RSM, the independent process parameters can be represented in quantitative form as:

$$
Y=f\left(X_{1}, X_{2}, X_{3}, \ldots X_{n}\right) \pm \varepsilon
$$

where, $Y$ is the response, $f$ is the response function, $\varepsilon$ is the experimental error, and $X_{1}$, $X_{2}, X_{3}, \ldots, X_{n}$ are independent variables.

The form of $f$ is unknown and may be very complex. RSM therefore aims to approximate $f$ using a suitable lower ordered polynomial in some region of the independent process variables. If the response can be well modeled by a linear function of the independent variables, Eq. (2) can be written as

$$
Y=\beta_{0}+\beta_{1} X_{1}+\beta_{2} X_{2}+\ldots \ldots \ldots+\beta_{n} X_{n}+\varepsilon
$$

On the other hand, the second-order model is normally used when the response function is nonlinear. However, if the model is not well fitted by the linear function then a higher order polynomial such as the quadratic model can be used. In the present study, both the linear model and second-order (quadratic model) model were studied. The experimental values were analyzed and a mathematical model then developed that illustrates the relationship between the process variable and the output (Kadirgama et al., 2009). The mathematical models based on a second-order polynomial are given as

$$
Y=\beta_{0}+\sum_{i=1}^{n} \beta_{i} X_{i}+\sum_{i=1}^{n} \beta_{i i} X_{i}^{2}+\sum_{i, j=1, i \neq j}^{n} \beta_{i j} X_{i} X_{j}+\varepsilon
$$

where $Y$ is the corresponding response, $X_{i}$ is the input variables, $X_{i}^{2}$ and $X_{i} X_{j}$ are the squares and interaction terms, respectively, of these input variables. $\beta_{o}, \beta_{i}, \beta_{i j}$ and $\beta_{i i}$ are the unknown regression coefficients. In this work, Eq. (4) can be rewritten according to the four variables used as:

$$
\begin{aligned}
Y= & \beta_{0}+\beta_{1} X_{1}+\beta_{2} \mathrm{X}_{2}+\beta_{3} \mathrm{X}_{3}+\beta_{4} \mathrm{X}_{4}+\beta_{11} \mathrm{X}_{1}^{2}+\beta_{22} \mathrm{X}_{2}^{2}+\beta_{33} \mathrm{X}_{3}^{2}+\beta_{44} \mathrm{X}_{4}^{2} \\
& +\beta_{12} X_{1} X_{2}+\beta_{13} X_{1} X_{3}+\beta_{14} X_{1} X_{4}+\beta_{23} X_{2} X_{3}+\beta_{24} X_{2} X_{4}+\beta_{34} X_{3} X_{4}
\end{aligned}
$$


where $X_{1}, X_{2}, X_{3}$, and $X_{4}$ are four input variables as peak current $\left(I_{p}\right)$, pulse-on time $\left(T_{o n}\right)$, pulse-off time $\left(T_{o f f}\right)$ and servo voltage $\left(S_{v}\right)$, respectively.

It is essential to check the adequacy of the fitted model, because an incorrect or under-specified model can lead to a confusing evaluation of the response. Whether the model is under specified can be verified by checking the fit of the model. For this purpose, analysis of variances (ANOVA) was performed. A confirmation test was conducted in order to test the accuracy of the model.

\section{RESULTS AND DISCUSSION}

\section{Model for Electrode Wear Rate}

Table 2 displays the coded value of the selected parameters as DOE, and the measured EWR during experiment. Analyses were performed using the experimental data through response surface methodology. Analysis of variance (ANOVA) was performed for both the single-order and second-order model. Model adequacy checking includes a test for significance of the regression model, model coefficients, and lack-of-fit. In this paper, the results for second-order modelling have been presented since it provided a more accurate result when compared with the single-order model. The results of the quadratic model for electrode wear rate, in the form of ANOVA, are given in Table 3 and 4. Table 3 shows the coefficients, standard errors on estimation of the coefficients 'SE coef' and p-value. P-value is used to determine whether a factor is significant or insignificant. Usually, it is compared against an alpha value of 0.05 as the F-ratio is calculated for a $95 \%$ confidence level. If the p-value is lower than 0.05 , the factor is significant. Accordingly, factor $X_{1}, X_{2}, X_{3}$ and $X_{4}$, interaction effect of factors except the effect of factor $X_{1}$ with factor $X_{4}$ and the second-order terms of factors $X_{1}, X_{2}, X_{3}$ and $X_{4}$ have significant effect.

Table 4 shows the results obtained using ANOVA, such as the coefficient of determination $\left(\mathrm{R}^{2}\right)$, standard deviation $(\mathrm{S})$, adjusted $\mathrm{R}^{2}$, predicted $\mathrm{R}^{2}$. The coefficient of determination is the ratio of the sum of squares of the predicted responses (corrected for the mean) to the sum of squares of the observed responses (also corrected for the mean) (Kansal et al., 2005). Generally, the higher the $\mathrm{R}^{2}$, the better the model fits the data, and it is always between 0 and $100 \%$. Standard deviation (S) is measured in units of the response variable and represents the standard distance that data values fall from the regression line (Kadirgama \& Abou-El-Hossein, 2005). For a given study, the better the equation predicts the response, the lower the value of $\mathrm{S}$. Adjusted $\mathrm{R}^{2}$ accounts for the number of predictors in the model that describe the significance of the relationship. Predicted $\mathrm{R}^{2}$ is used in regression analysis to indicate how well the model predicts responses for new observations. Larger values of predicted $\mathrm{R}^{2}$ suggest a model of greater predictive ability. The value of $\mathrm{R}^{2}$ (R-squared) and adjusted $\mathrm{R}^{2}$ is over $99 \%$. This means that the mathematical model provides an excellent explanation of the relationship between the independent variables (factors) and the response (EWR). Similarly, the obtained values of standard deviation and $\mathrm{R}^{2}$ - predicted evidence that the proposed model is adequate to predict the response. The associated P-value for the model is lower than 0.05 (i.e. $\alpha=0.05$, or $95 \%$ confidence), which indicates that the model is considered statistically significant. When the p-value is less than the $\alpha$-level, this suggests that the model does not accurately fit the data. The p-value for the lack-offit is 0.191 , which is larger than 0.05 (i.e. $\alpha=0.05$, or $95 \%$ confidence) (Kadirgama $\&$ 
Abou-El-Hossein, 2005). Thus, the lack-of-fit term is insignificant as it is desired. The fit summary recommended that the quadratic model is statistically significant for analysis of EWR, therefore, based on equation (5), the mathematical relation for correlating the electrode wear rate and the above mentioned process variables is obtained as follows:

$$
\begin{aligned}
T W R= & 1.34155-0.0619188 I_{p}-0.0111534 T_{o n}+0.00354923 T_{o f f}+0.0118027 S_{v} \\
& +0.00335602 I_{p}^{2}+9.91020 \times 10^{-6} T_{o n}^{2}-7.35223 \times 10^{-6} T_{o f f}^{2}-1.24916 \times 10^{-4} S_{\mathrm{v}}^{2} \\
& -1.23759 \times 10^{-4} I_{p} T_{o n}-6.01964 \times 10^{-5} I_{p} T_{o f f}-2.63756 \times 10^{-5} I_{p} S_{v} \\
& +7.81620 \times 10^{-6} T_{o n} T_{o f f}+5.35383 \times 10^{-5} T_{o n} S_{v}-1.78650 \times 10^{-5} T_{o f f} S_{v}
\end{aligned}
$$

\begin{tabular}{|c|c|c|c|c|}
\hline \multicolumn{4}{|c|}{ Process parameters } & \multirow{2}{*}{$\begin{array}{c}\text { Observed value } \\
\begin{array}{c}\text { EWR } \\
(\mathrm{mg} / \mathrm{min})\end{array}\end{array}$} \\
\hline $\begin{array}{c}\text { Peak current } \\
\text { (A) }\end{array}$ & $\begin{array}{l}\text { Pulse-on } \\
\text { time }(\mu \mathrm{s})\end{array}$ & $\begin{array}{l}\text { Pulse-off } \\
\text { time }(\mu \mathrm{s})\end{array}$ & $\begin{array}{c}\text { Servo- } \\
\text { voltage (V) }\end{array}$ & \\
\hline 0 & 0 & 0 & 0 & 0.2034 \\
\hline-1 & 1 & 1 & -1 & 0.2707 \\
\hline 2 & 0 & 0 & 0 & 0.9024 \\
\hline 0 & 0 & 0 & 0 & 0.2072 \\
\hline 0 & 0 & 0 & -2 & 0.2700 \\
\hline 0 & 0 & 0 & 0 & 0.2094 \\
\hline-1 & -1 & -1 & -1 & 0.6800 \\
\hline 1 & 1 & 1 & -1 & 0.1233 \\
\hline-1 & 1 & 1 & 1 & 0.2238 \\
\hline 0 & 0 & 0 & 0 & 0.2022 \\
\hline-1 & -1 & 1 & 1 & 0.4159 \\
\hline 0 & 0 & -2 & 0 & 0.1321 \\
\hline-1 & 1 & -1 & -1 & 0.1583 \\
\hline 1 & -1 & -1 & 1 & 0.7432 \\
\hline 1 & -1 & 1 & 1 & 0.5444 \\
\hline-1 & -1 & -1 & 1 & 0.4946 \\
\hline 1 & 1 & 1 & 1 & 0.0774 \\
\hline 1 & 1 & -1 & -1 & 0.1086 \\
\hline-2 & 0 & 0 & 0 & 0.8192 \\
\hline 0 & 0 & 0 & 0 & 0.2052 \\
\hline 0 & 0 & 2 & 0 & 0.0622 \\
\hline 0 & 0 & 0 & 0 & 0.1983 \\
\hline 1 & -1 & 1 & -1 & 0.7860 \\
\hline 1 & 1 & -1 & 1 & 0.0922 \\
\hline 1 & -1 & -1 & -1 & 0.9289 \\
\hline 0 & 0 & 0 & 2 & 0.0361 \\
\hline-1 & 1 & -1 & 1 & 0.1568 \\
\hline 0 & -2 & 0 & 0 & 0.9874 \\
\hline-1 & -1 & 1 & -1 & 0.6421 \\
\hline 0 & 2 & 0 & 0 & -0.0086 \\
\hline 0 & 0 & 0 & 0 & 0.2085 \\
\hline
\end{tabular}

Table 2. Experimental results for EWR according to the design of experiment (with coded value of the parameters). 
Table 3. ANOVA (estimated regression coefficients) for EWR.

\begin{tabular}{lclc}
\hline \multicolumn{1}{c}{ Term } & Coefficient & SE coefficient & P-value \\
\hline Constant & 1.34155 & 0.001912 & 0.000 \\
$I_{p}(\mathrm{~A})$ & -0.0619188 & 0.001033 & 0.000 \\
$T_{o n}(\mu \mathrm{s})$ & -0.0111534 & 0.001033 & 0.000 \\
$T_{\text {off }}(\mu \mathrm{s})$ & 0.00354923 & 0.001033 & 0.000 \\
$S_{v}(\mathrm{~V})$ & 0.0118027 & 0.001033 & 0.000 \\
$I_{p}(\mathrm{~A}) \times I_{p}(\mathrm{~A})$ & 0.00335602 & 0.000946 & 0.000 \\
$T_{\text {on }}(\mu \mathrm{s}) \times T_{\text {on }}(\mu \mathrm{s})$ & 0.0000099102 & 0.000946 & 0.000 \\
$T_{\text {off }}(\mu \mathrm{s}) \times T_{\text {off }}(\mu \mathrm{s})$ & -0.00000735223 & 0.000946 & 0.000 \\
$S_{v}(\mathrm{~V}) \times S_{v}(\mathrm{~V})$ & -0.000124916 & 0.000946 & 0.000 \\
$I_{p}(\mathrm{~A}) \times T_{o n}(\mu \mathrm{s})$ & -0.000123759 & 0.001265 & 0.000 \\
$I_{p}(\mathrm{~A}) \times T_{o f f}(\mu \mathrm{s})$ & -0.0000601964 & 0.001265 & 0.000 \\
$I_{p}(\mathrm{~A}) \times S_{v}(\mathrm{~V})$ & -0.0000263756 & 0.001265 & 0.164 \\
$T_{o n}(\mu \mathrm{s}) \times T_{\text {off }}(\mu \mathrm{s})$ & 0.00000781620 & 0.001265 & 0.000 \\
$T_{o n}(\mu \mathrm{s}) \times S_{v}(\mathrm{~V})$ & 0.0000535383 & 0.001265 & 0.000 \\
$T_{o f f}(\mu \mathrm{s}) \times S_{v}(\mathrm{~V})$ & -0.0000178650 & 0.001265 & 0.000 \\
\hline
\end{tabular}

Table 4. ANOVA Table for electrode wear rate.

\begin{tabular}{lccccc}
\hline Source & DOF & Sum of squares & Mean squares & F-ratio & $\mathrm{P}$ \\
\hline Regression & 14 & 2.72470 & 0.194621 & 7601.73 & 0.000 \\
Linear & 4 & 1.61069 & 0.402671 & 15727.98 & 0.000 \\
Square & 4 & 0.95657 & 0.239143 & 9340.72 & 0.000 \\
Interaction & 6 & 0.15744 & 0.026240 & 1024.90 & 0.000 \\
Residual error & 16 & 0.00041 & 0.000026 & & \\
Lack-of-Fit & 10 & 0.00032 & 0.000032 & 2.08 & 0.191 \\
$\quad$ Pure Error & 6 & 0.00009 & 0.000015 & & \\
Total & 30 & 2.72511 & & & \\
Standard deviation $(\mathrm{S})=0.00505986$ & & & \\
$\mathrm{R}^{2}=99.98 \%$ \\
$\mathrm{R}^{2}$-adjusted =99.97\%
\end{tabular}

\section{Confirmation Experiments}

The data from the confirmation test, and the comparisons with the predicted value for EWR are listed in Table V. From the analysis, it can be observed that the calculated error is small. A confirmation test establishes the error of the mathematical model for EWR $5.13 \%$ to $6.70 \%$ with a mean value $5.74 \%$ when the polarity is positive. This clearly confirms the excellent reproducibility of the experimental conclusions.

\section{Minimum EWR}

Statistical analysis was also performed in order to determine the minimum electrode wear rate. In this study, negative electrode wear is evidenced for particular settings. The paper reveals that a combination of $15 \mathrm{~A}$ peak current, $350 \mu \mathrm{s}$ pulse-on time, $180 \mu \mathrm{s}$ pulse-off time and $95 \mathrm{~V}$ servo-voltage along with positive polarity causes negative tool 
wear. Consequently, the maximum negative tool wear rate $(-0.4049 \mathrm{mg} / \mathrm{min})$ is found in the combination of $I_{p}=16.5 \mathrm{~A}, T_{o n}=350 \mu \mathrm{s}, T_{\text {off }}=60 \mu \mathrm{s}$ and $S_{v}=75 \mathrm{~V}$. This can be explained by the molten materials accumulated on the electrode surface near to the workpiece during machining. This foreign material is attached with the tool surface and protects the tool electrode surface against wear. Observation also revealed that more tool wear exists in the early stage of machining since the initial surface of the tool is not covered with workpiece material, afterwards wear rate decreases.

Table 5. Results from confirmation experiment.

\begin{tabular}{ccccccc}
\hline$I_{p}(\mathrm{~A})$ & $T_{\text {on }}(\mu \mathrm{s})$ & $T_{\text {off }}(\mu \mathrm{s})$ & $S_{v}(\mathrm{~V})$ & \multicolumn{2}{c}{ EWR $(\mathrm{mg} / \mathrm{min})$} & \multirow{2}{*}{ Error $(\%)$} \\
\cline { 5 - 6 } & & & & Expt. & Pred. & \\
\hline 15 & 180 & 120 & 85 & 0.2204 & 0.2317 & 5.13 \\
5 & 95 & 120 & 85 & 0.8570 & 0.7996 & 6.70 \\
22 & 265 & 240 & 75 & 0.1186 & 0.1116 & 5.90 \\
8 & 95 & 60 & 85 & 0.6574 & 0.6229 & 5.24 \\
& & & & & Average & 5.74 \\
\hline
\end{tabular}

\section{CONCLUSIONS}

This paper attempted to develop a mathematical model that accurately correlates the process variables and machining performance, electrode wear rate of EDM process on Ti-5Al-2.5Sn with graphite electrode. A mathematical model was developed based on response surface methodology utilizing experimental data. The fitness of the model was verified by employing analysis of variance through RSM. The accuracy of the developed model was found to have an average error of $5.74 \%$. Thus, the comprehensive models were found to be adequate and to correlate EWR with the four process variables. These mathematical models can successfully predict the performance characteristics of EDM in terms of the electrode wear of a graphite electrode in an EDM process on Ti-5Al-2.5Sn. The study also aimed to establish the combination of the four process parameters which gives lower erosion of the graphite electrode during electrical discharge machining on selected titanium material. Negative tool wear was found with a combination of $15 \mathrm{~A}$ peak current, $350 \mu$ s pulse-on time, $180 \mu$ s pulse-off time and $95 \mathrm{~V}$ servo voltage. In addition, the combination of $I_{p}=16.5 \mathrm{~A}, T_{o n}=350 \mu \mathrm{s}, T_{o f f}=60 \mu \mathrm{s}$ and $S_{v}$ $=75 \mathrm{~V}$ yields maximum negative electrode wear rate.

\section{ACKNOWLEDGEMENTS}

The authors are obliged to the University of Malaysia Pahang for providing laboratory facilities and financial assistance under project no. RDU110110 and the Doctoral Scholarship Scheme (GRS 090335).

\section{REFERENCES}

Dave, H. K., Desai, K. P., \& Raval, H. K. (2012). Modeling and analysis of material removal rate during electro discharge machining of inconel 718 under orbital tool movement. International Journal of Manufacturing Systems, 2(1), 12-20.

Hascalik, A., Caydas, U., \& Gurun, H. (2007). Effect of traverse speed on abrasive waterjet machining of Ti-6Al-4V alloy. Materials and Design, 28, 1953-1957. 
Kadirgama, K., \& Abou-El-Hossein, K. A. (2005). Force prediction model for milling 618 stainless steel using response surface methodology. American Journal of Applied Sciences, 2(8), 1222.

Kadirgama, K., Noor, M., Rahman, M., Bakar, R. A., \& Hossein, A.-E. (2009). Fourth order torque prediction model in end milling. Journal of Applied Sciences, 9(13).

Khan, M., Rahman, A., Rahman, M., Noor, M., Kadirgama, K., \& Maleque, M. (2011a). Current research trends on dry, near-dry and powder mixed electrical discharge machining. Advanced Materials Research, 264, 956-961.

Khan, M. A. R., Rahman, M. M., Kadirgama, K., \& Ismail, A. R. (2012). Rsm model to evaluate material removal rate in edm of Ti-5Al-2.5Sn using graphite electrode.

Khan, M. A. R., Rahman, M. M., Kadirgama, K., Maleque, M. A., \& Bakar, R. A. (2011b). Artificial intelligence model to predict surface roughness of Ti-15-3 alloy in edm process. World Academy of Science, Engineering and Technology, 74, 198-202.

Khan, M. A. R., Rahman, M. M., Kadirgama, K., Maleque, M. A., \& Ishak, M. (2011c). Prediction of surface roughness of ti-6al-4v in electrical discharge machining: A regression model. Journal of Mechanical Engineering and Sciences, 1, 16-24.

Kumar, S., \& Singh, R. (2010). Investigation of surface properties in manganese powder mixed electrical discharge machining of OHNS and D2 die steels. International Journal of Automotive and Mechanical Engineering, 2, 181-199.

Najiha, M., Rahman, M., Kamal, M., Yusoff, A., \& Kadirgama, K. (2012). Minimum quantity lubricant flow analysis in end milling processes: A cfd approach. Journal of Mechanical Engineering and Sciences, 3, 340-345.

Perazolli, L., Simoes, A. Z., Coleto, J., U, \& Moura Filho, F. (2005). Structural and tidoped wo3 ceramics. Journal of Material Sciences, 23, 2229-2234.

Rahman Khan, M. A., Rahman, M. M., Kadirgama, K., \& Ismail, A. R. (2012). Mathematical model for wear rate of negative graphite electrode in electrical discharge machining on ti-5a1-2.5sn. Jurnal Teknologi (Sciences and Engineering), 59(SUPPL.2), 55-59.

Rahman, M. M. (2011) Optimization of process parameters on ti-6al-4v using central composite design method. Advanced Materials Research, 189-193, 1393-1400.

Rahman, M. M., Khan, M. A. R., Kadirgama, K., Noor, M. M., \& Bakar, R. A. (2010a). Mathematical modeling of material removal rate for ti-5al-2.5sn through edm process: A surface response method European Conference of Chemical Engineering, ECCE'10, European Conference of Civil Engineering, ECCIE'10, European Conference of Mechanical Engineering, ECME'10, European Conference of Control, ECC'10 , pp. 34-37.

Rahman, M. M., Khan, M. A. R., Kadirgama, K., Noor, M. M., \& Bakar, R. A. (2010b). Modeling of material removal on machining of ti-6al-4v through edm using copper tungsten electrode and positive polarity. World Academy of Science, Engineering and Technology, 71, 576-581.

Rahman, M. M., Khan, M. A. R., Kadirgama, K., Noor, M. M., \& Bakar, R. A. (2011a) Optimization of machining parameters on tool wear rate of Ti-6Al-4V through edm using copper tungsten electrode: A statistical approach. Advanced Materials Research, 152-153, 1595-1602.

Rahman, M. M., Khan, M. A. R., Noor, M. M., Kadirgama, K., \& Bakar, R. A. (2011b). Optimization of machining parameters on surface roughness in edm of Ti-6Al4V using response surface method Advanced Materials Research, 213, 402-408. 
Singh, R., \& Singh, B. (2011). Comparison of cryo-treatment effect on machining characteristics of titanium in electric discharge machining. International Journal of Automotive and Mechanical Engineering, 3, 239-248.

Wang, H., Gan, Y., Dong, X., Peng, S., Dong, L., \& Wang, Y. (2012). Thermoelectric properties of ti-doped wo3 ceramics. Journal of Material Sciences, 23, 22292234.

Yusoff, A. R., Mohamed Suffian, M. R. Z., \& Taib, M. Y. (2011). Literature review of optimization technique for chatter suppression in machining. Journal of Mechanical Engineering and Sciences, 1, 47-61. 